\title{
Novel expression profiles and invasiveness-related biology function of DKK1 in endometrial carcinoma
}

\author{
NUO YI ${ }^{1}$, QIN-PING LIAO ${ }^{1}$, TING $^{2}{ }^{2}$ and YAN XIONG ${ }^{2}$ \\ Departments of ${ }^{1}$ Obstetrics and Gynecology and ${ }^{2}$ Pathology, Peking University First Hospital, Beijing 100034, P.R. China
}

Received December 10, 2008; Accepted February 4, 2009

DOI: $10.3892 /$ or_00000370

\begin{abstract}
DKK1 is a negative regulator in the Wnt signal transduction pathway. It can inhibit the pathway's activation. Previous studies in some malignant tumors revealed the possibility that DKK1 is involved in tumorigenesis inducing abnormalities of the Wnt signal pathway. In this study, we showed that in benign and malignant endometrium, DKK1 exhibited novel expression profiles and invasiveness-related biology function: DKK1 was expressed in both glandular epithelium and matrix of two kinds of endometrium tissues and mostly distributed in the cytoplasm and epicytes of endometrial carcinoma (EC) Ishikawa cell line. DKK1 expression level in EC was significantly lower than that in benign endometrium. The expression correlated well with histology and clinical stage of EC. Exogenous DKK1 suppressed invasiveness of EC cells. Taken together, DKK1 is involved in genesis and early phase of EC by suppressing the invasiveness via the Wnt signal pathway. It shows promise as a biomarker for screening the progression of EC.
\end{abstract}

\section{Introduction}

The worldwide incidence of EC, one of the female genital tract malignant tumors has notably increased over the years. Several studies have focused on this field. Previous studies revealed that abnormalities of Wnt signaling transduction pathway induced genesis and development of some human malignant tumors $(1,2)$. Attempts have been made to investigate some regulators in the Wnt signaling pathway as targets for diagnosis and treatment of malignant tumors.

As a negative regulator in Wnt signaling pathway, DKK1 can inhibit its activation (3-5). Former studies in colorectum

Correspondence to: Dr Qin-Ping Liao, Department of Obstetrics and Gynecology, Peking University First Hospital, 1 Xi'an men Street, Beijing 100034, P.R. China

E-mail: qinping_liao@sohu.com

Abbreviations: EC, endometrial carcinoma; LRP 5/6, lipoprotein receptor-related protein $5 / 6$

Key words: DKK1, endometrial carcinoma, benign endometrium, invasiveness and placenta showed that DKK1 was prominently expressed in normal cells but absent in cancer cells. At present, research on DKK1 expression profiles and biology function in genesis and development of EC is scarce. Our study is focused on this point.

\section{Materials and methods}

Clinical materials. Endometrium samples were taken from patients admitted to Department of Obstetrics and Gynecology in Peking University First Hospital from 2005 to 2007. All selected cases were classified into two groups: EC group (30 cases) and benign endometrium group (34 cases). The median age in EC group was 59.53 (range 41-78) and 43.07 in benign endometrium group (range 26-71). The median age of the two groups was not significantly different. Detailed characteristics of the patients are shown in Table I. A total of 64 paraffin-embedded sections were obtained for immunohistochemistry staining from Department of Pathology at Peking University First Hospital to detect DKK1 expression.

EC cell line and cell culture. In this study, EC Ishikawa cell line was used for immunofluorescence to observe DKK1 intracellular position expression. Cell line was obtained from American Type Culture Collection (ATCC). Cells were maintained in DMEM/F12 (Gibco Co.) supplemented with $2 \mathrm{mM}$ L-glutamine, $1 \%$ penicillin and streptomycin and $10 \%$ fetal bovine serum (PAA Laboratories) and grown at $37^{\circ} \mathrm{C}$ in humidified air with $5 \% \mathrm{CO}_{2}$.

Immunohistochemistry staining. PicTure ${ }^{\mathrm{TM}}$ histostaining reagent (Zymed Laboratories) was used for immunohistochemistry staining. The staining procedure was performed as described previously $(6,7)$ with some modifications. After deparaffinization, hydration and heat recovery, sections were blocked by $3 \% \mathrm{H}_{2} \mathrm{O}_{2}$ for $10 \mathrm{~min}$ and incubated with DKK1 mouse monoclonal antibody (M08, clone 2B12, GenBank accession no. AAH01539, Abnova Co.; diluted in PBS, 1:300) overnight at $4^{\circ} \mathrm{C}$. Sections were then incubated with horseradish peroxidase-conjugated goat anti-mouse secondary antibody (Santa Cruz Biotechnology, Inc; diluted in PBS, 1:5000) for $1 \mathrm{~h}$ and stained by DAB for $2 \mathrm{~min}$ at room temperature. Finally, sections were detected with a light microscope (Olympus) at a magnification of x200. PBS was used as negative control. 
Immunocytochemistry and immunofluorescence staining. The staining procedure was carried out as described (8) with some modifications. After being fixed with methanol and acetone $(1: 1 \mathrm{v} / \mathrm{v})$ for $10 \mathrm{~min}$ at $-10^{\circ} \mathrm{C}$, Ishikawa cells were blocked by $3 \%$ bovine serum albumin for $20 \mathrm{~min}$ and stained with DKK1 antibody (diluted in PBS, 1:300) overnight at $4^{\circ} \mathrm{C}$. Cells were then stained with FITC-conjugated affinipure goat anti-mouse secondary antibody (Santa Cruz Biotechnology, Inc; diluted in PBS, 1:50) for $1 \mathrm{~h}$ at $37^{\circ} \mathrm{C}$ and a nuclear stain with propidium iodide (Sigma-Aldrich Co., diluted in PBS, $0.005 \mathrm{mg} / \mathrm{ml}$ ) for $10 \mathrm{~min}$ at room temperature. Images were obtained with a confocal fluorescence microscope (Nikon) at a magnification of $x 600$. The staining procedure of active- $\beta$ catenin (1:300 dilution in PBS) was similar to DKK1.

Western blot analysis. Western blot analysis was performed as described previously (9) with some modifications. Cell lysate samples were generated from Ishikawa cells treated with $0.2 \mathrm{mg} / \mathrm{ml}$ of recombinant human DKK1 (R\&D systems) for $72 \mathrm{~h}$. Cell lysate samples without DKK1 were used as control. SDS-polyacrylamide gel electrophoresis was performed on cell lysate samples and the proteins were transfered to nitrocellulose. The blotted nitrocellulose was blocked in freshly prepared PBS containing 5\% non-fat dry milk and $0.2 \%$ Tween for $1 \mathrm{~h}$ at room temperature with constant agitation and incubated with active- $\beta$-catenin mouse monoclonal antibody (clone 8E4, GenBank accession no. AY413766, Upstate Biotechnology; diluted in PBS, 1:500) with agitation overnight at $4^{\circ} \mathrm{C}$. The nitrocellulose was then incubated with horseradish peroxidase-conjugated goat antimouse secondary antibody (diluted in PBS, 1:5000) for $1 \mathrm{~h}$ at room temperature with agitation. The protein signals were detected by an enhanced chemiluminescence detection of Western blots (Santa Cruz Biotechnology, Inc).

Chamber invasiveness assay in vitro. Invasiveness of Ishikawa cells was measured by chamber invasiveness assay as described previously (10-13) with some modifications. Membranes with $8-\mu \mathrm{m}$ pores in 24-well chamber (Millipore Co.) were coated with matrigel matrix (BD Biosciences; diluted in DMEM/F12, 1:9 v/v). After treatment with 0.2 $\mathrm{mg} / \mathrm{ml}$ of exogenous DKK1 for $24 \mathrm{~h}$, cells were trypsinized and counted with a hemocytometer using trypan blue, and viable cells were seeded into the upper chamber at $2 \times 10^{5}$ cells/well in serum-free DMEM/F12 and $0.5 \mathrm{ml}$ of DMEM/ F12 supplemented with $10 \%$ fetal bovine serum was placed in the bottom well. Incubation was carried out for $24 \mathrm{~h}$ at $37^{\circ} \mathrm{C}$ in humidified air with $5 \% \mathrm{CO}_{2}$. After $24 \mathrm{~h}$, cells in the upper chamber were carefully removed with a cotton-tip. Cells on the lower surface were fixed with methanol for $10 \mathrm{~min}$ at $-10^{\circ} \mathrm{C}$ and stained by hematoxylin and eosin. Cells untreated with DKK1 were used as control. Cell number penetrating matrigel matrix and pore was counted.

Result assessment. Immunohistochemistry staining. Staining was analyzed and scored on the following scale according to percentage of positive expression EC cells:,$-<10 \% ;+, 10-25 \%$; ,$++ 26-50 \%$; +++, $>50 \%$. Cases with - or + staining were classified as low expression and cases with ++ or +++ were classified as high expression.
Table I. Detailed characteristics of the patients.

\begin{tabular}{lc}
\hline Groups & No. of cases \\
\hline Benign endometrium & 34 \\
Proliferating stage & 19 \\
Pro-gestation stage & 15 \\
Endometrial carcinoma & 30 \\
Pathological categories & \\
Endometrial adenocarcinoma & 17 \\
Others & 13 \\
Histological differentiation & \\
Well-differentiated & 16 \\
Moderate differentiated, low-differentiated & \\
and undifferentiated & 14 \\
Clinical stage (FIGO 2000) & \\
Stage I & 17 \\
Stage II, III and IV & 13 \\
Lymph node metastasis & \\
No & 27 \\
Yes & 3 \\
\hline
\end{tabular}

Immunocytochemistry and immunofluorescence. DKK1 positive expression appeared as green fluorescence (stained by FITC); Cell nucleus-positive expression appeared as red fluorescence (stained by Propidium Iodide). Active- $\beta$-catenin positive expression also appeared as green fluorescence (stained by FITC).

Invasiveness assay. Invasiveness was quantified by counting cell number penetrating matrigel matrix and pore in 10 random fields with a light microscope (Olympus) at a magnification of x200. The mean value was calculated from data obtained from three separate chambers.

Statistical analysis. All data were analyzed with SAS version 9.0 (SAS Institute, Cary, NC). Statistically significant differences were defined as $\mathrm{P}<0.05$. Differences of DKK1 expression level in benign and malignant endometrium were evaluated by Chi-square test. DKK1 expression level was assessed for correlations with clinicopathological characteristics using Fisher's exact probabilities in $2 \times 2$ table. Alteration of active- $\beta$-catenin expression level was evaluated by Student's t-test. For cell invasiveness assay, data were analyzed by Student's t-test.

\section{Results}

Location of DKK1 expression in benign and malignant endometrium tissues. DKK1 was expressed in both glandular epithelium and matrix of benign and malignant endometrium tissues. In addition, the expression in glandular epithelium was stronger than that in the matrix (Fig. 1).

DKK1 intracellular position expression in EC Ishikawa cells. DKK1 expression (green fluorescence) was mostly distributed 
A

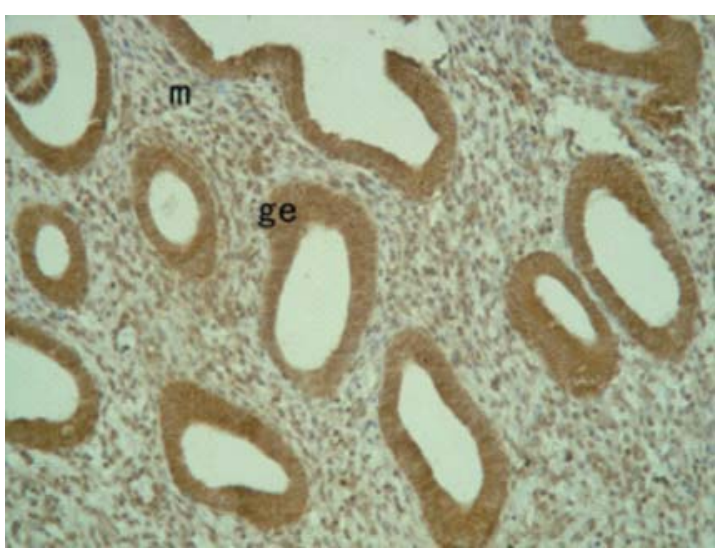

B

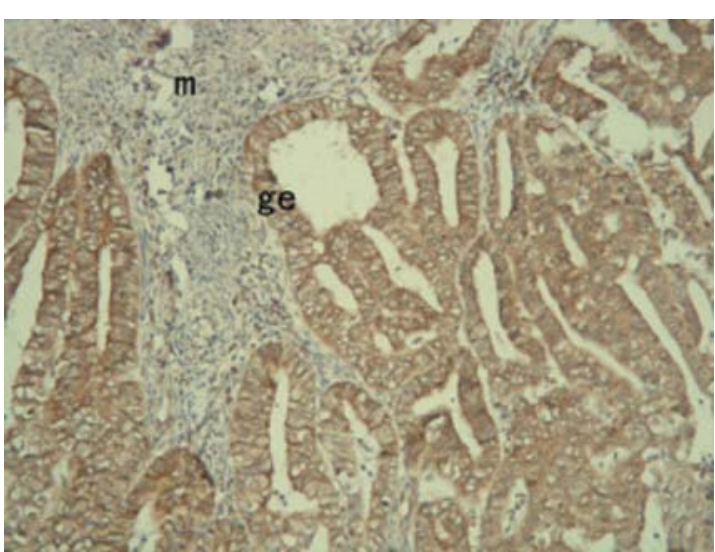

Figure 1. DKK1 expression location in benign endometrium and endometrial carcinoma. DKK1 expression is seen in both glandular epithelium and the matrix of the benign endometrium (A) and endometrial carcinoma tissues (B). The expression in glandular epithelium was stronger than that in the matrix. ge, Glandular epithelium and m, matrix. Immunohistochemistry x200.

Table II. DKK1 expression level in benign endometrium and endometrial carcinoma.

\begin{tabular}{ccccc}
\hline Groups & No. of & No. of low & & No. of high \\
samples & expression & expression \\
& - & + & ++ & +++ \\
\hline
\end{tabular}

\begin{tabular}{lccccc}
\hline $\begin{array}{l}\text { Benign } \\
\text { endometrium }\end{array}$ & 34 & 7 & 5 & 10 & 12 \\
$\begin{array}{l}\text { Endometrial } \\
\text { carcinoma }\end{array}$ & 30 & 9 & 11 & 6 & 4 \\
\hline
\end{tabular}

in the cytoplasm and epicytes of the Ishikawa cells. Cell nucleus appeared as red fluorescence (Fig. 2).

Comparison of DKK1 expression level between benign endometrium and EC tissues. In benign endometrium group, DKK1 was highly expressed in $64.71 \%(22 / 34)$ and at low level in $35.29 \%$ (12/34). In EC group, DKK1 expression level was high in $10 / 30(33.33 \%)$ and low in 20/30 (66.67\%), respectively. DKK1 expression level in EC tissues was significantly lower than that in benign endometrium tissues (Chi-square test, $\mathrm{P}<0.05$; Table II).

Alterations of active- $\beta$-catenin expression level and intracellular position pattern by DKK1 in EC Ishikawa cells. Treatment with DKK1, decreased the active- $B$-catenin expression level by $9.99 \%$ ( $24 \mathrm{~h}$ ), $22.04 \%$ (48 h), $34.56 \%$ (72 h), respectively. The expression level was down-regulated by DKK1 (Student's t-test, $\mathrm{P}<0.01 ;$ Fig. 3).

Active- $\beta$-catenin (green fluorescence) was intensely stained in the cytoplasm and nucleus of Ishikawa cells (Fig. 4A). Treatment with DKK1 for $24 \mathrm{~h}$, resulted in diffused active- $\beta$-catenin staining in the nucleus and only weak staining was localized to the cytoplasm (Fig. 4B).

Correlation between DKK1 expression level and clinicopathological characteristics in EC tissues. In 30 EC samples, DKK1 expression level in well-differentiated EC was higher than that in the moderate differentiated, low differentiated and undifferentiated samples (Fisher's exact probabilities, $\mathrm{P}<0.05)$. Similarly, DKK1 expression level in EC at clinical stage I was significantly higher than those at stage II, III and IV (Fisher's exact probabilities, $\mathrm{P}<0.01$ ). However, it did not show any correlations between pathology categories and lymph node metastasis (Fisher's exact probabilities, $\mathrm{P}>0.05$; Table III).

Invasiveness-related biology function of DKK1 in EC Ishikawa cells. Treatment with DKK1 for $24 \mathrm{~h}$, average cell number (105.40) penetrating matrigel matrix and pore was decreased as compared to control group (129.70) (Student's t-test, $\mathrm{P}<0.01$; Fig. 5). Therefore, exogenous DKK1 suppressed invasiveness of EC cells.

\section{Discussion}

Endometrial carcinoma (EC) is one of malignant tumors that severely impacts female health. For the past few years, EC has become the female genital tract malignant tumor with the highest incidence in Western countries (14).

Abnormalities in cell signaling transduction pathway are often correlated with tumorigenesis. Wnt signaling transduction pathway abnormalities are revealed to be closely related with many common malignant tumors such as colon cancer, malignant melanoma and chest carcinoma via multiple mechanisms including cell proliferation, differentiation, apoptosis, adherence, invasion, and migration (3-5). Attempts have been made to study several molecules in Wnt signaling pathway as targets for diagnosis and treatment of malignant tumors.

Wnt signaling pathway consists of highly conserved secreted ligands that bind cell-surface receptors called frizzled and LRP 5/6 (co-receptor of frizzled receptor) (15). ß-catenin, a component in Wnt pathway largely displays the state of the pathway. In the absence of Wnt signaling, $\beta$-catenin in cytoplasm is phosphorylated (16) and rapidly degraded by the ubiquitin system (17). In the presence of Wnt signaling, signaling interacting with frizzled and LRP 5/6 leads to dephosphorylation of $\beta$-catenin (non-phospho: active form of 
$\mathbf{A}$

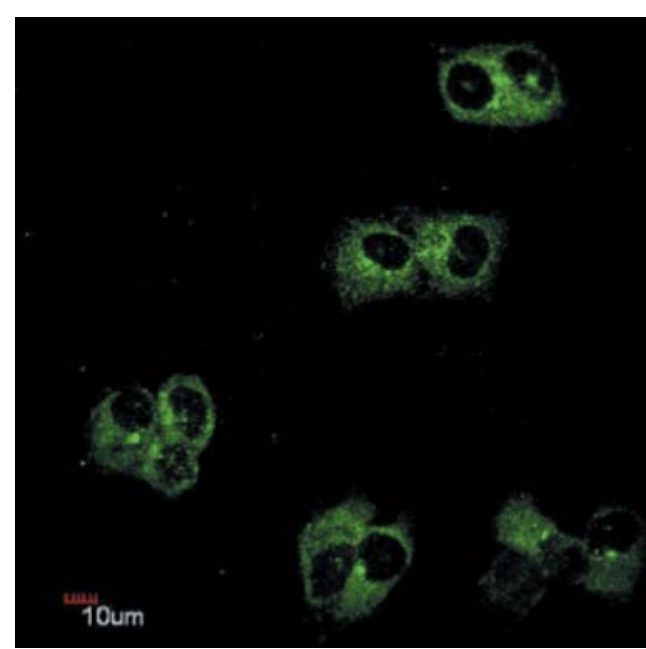

B

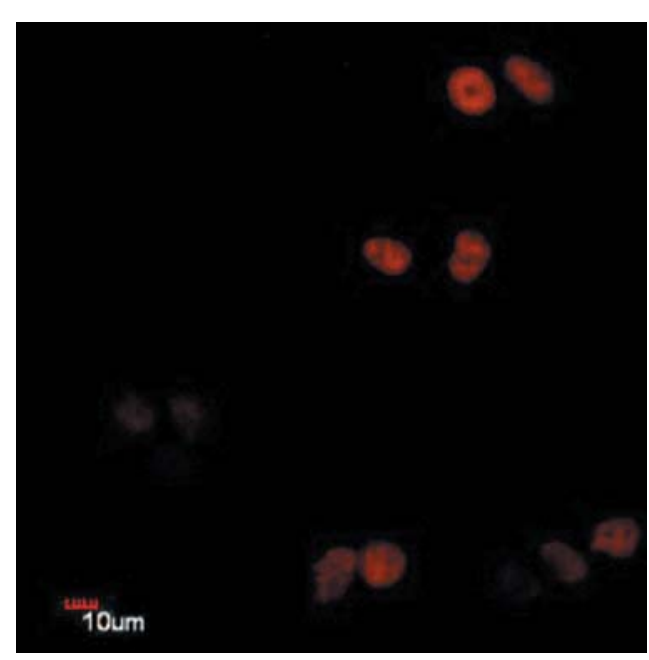

C

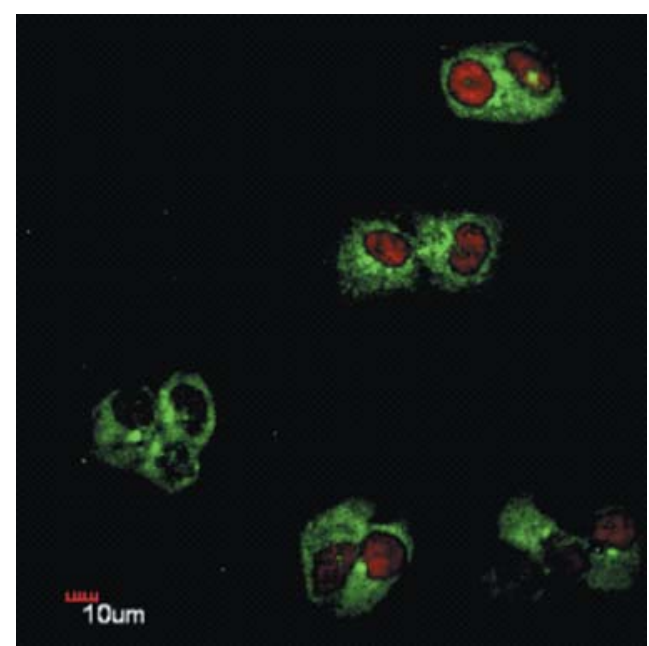

Figure 2. DKK1 intracellular position expression in EC Ishikawa cells. Green fluorescence mostly appeared in the cytoplasm and epicytes. Cell nucleus appeared as red fluorescence. DKK1 was mostly seen in the cytoplasm and epicytes of Ishikawa cells. Immunofluorescence x600 Bar = $10 \mu \mathrm{m}$.

$\beta$-catenin). Active- $\beta$-catenin is accumulated in cytoplasm, translocated into nucleus and combined with lymphocyte enhancer factor/T-cell factor of transcription factors to activate
A

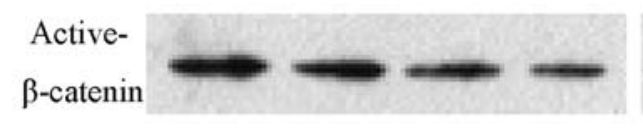

$\beta$ - actin

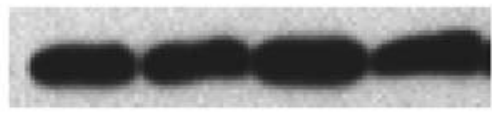

$\begin{array}{llll}1 & 2 & 3 & 4\end{array}$

B

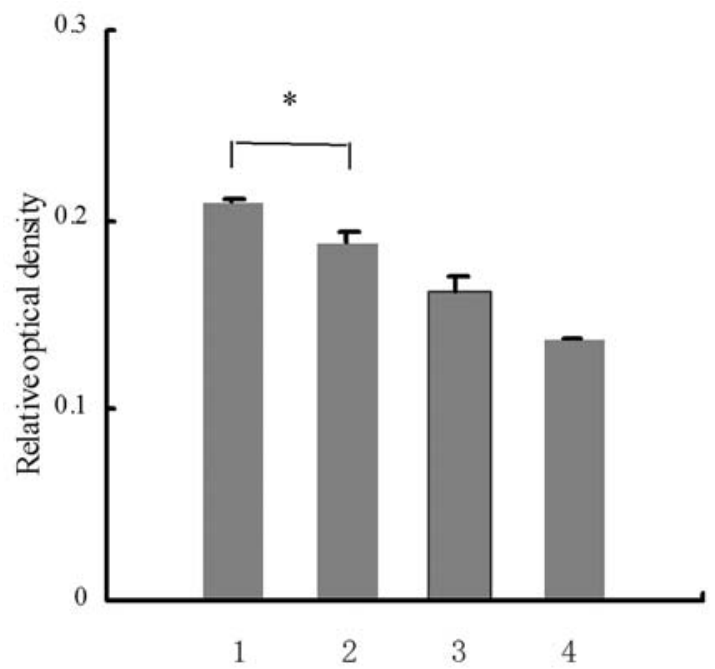

Figure 3. Alterations of active- $\beta$-catenin expression level by DKK1 in EC Ishikawa cells. (1) Control, relative optical density $(\mathrm{ROD})=0.2092$; Treatment with DKK1: (2) $24 \mathrm{~h}, \mathrm{ROD}=0.1883$; (3) $48 \mathrm{~h}, \mathrm{ROD}=0.1631$; (4) $72 \mathrm{~h}, \mathrm{ROD}=0.1369$. Active- $\beta$-catenin expression level was decreased by 9.99\% (24 h), 22.04\% (48 h), 34.56\% (72 h), respectively. Active-B-catenin was down-regulated by DKK1. $\mathrm{P}<0.01$.

downstream target genes, many of which are involved in genesis and development of oncology (18-20). B-catenin has been shown to play a crucial role in the pathway. Thus, Wnt signaling pathway has been implicated in pathogenesis and progression of some human malignancies, including melanoma, myeloma and lung cancer (21-23).

Our study focused on DKK1 - a secreted glycoprotein in Wnt signal pathway $(24,25)$. It is one member of DKK family (DKKs). The human DKK1 (chromosome 10q11.2) gene encodes an inhibitor of Wnt signaling pathway by binding to and antagonizing LRP 5/6 $(26,27)$.

Firstly, we detected DKK1 expression location in benign endometrium and EC. Similar tissue locations were shown in two kinds of tissues. Furthermore, we observed that DKK1 intracellular location expression was mostly distributed in the cytoplasm and epicytes of EC Ishikawa cells (Figs. 1 and 2).

Next, we examined DKK1 expression levels in the two tissue types. However, the expression levels were quite different. DKK1 high expression level was dominant in benign tissues. In contrast, low expression level was dominant in carcinoma tissues. The reduction trend of DKK1 expression level was likely coincidence with its negative regulatory function in Wnt signaling pathway. 
Aa

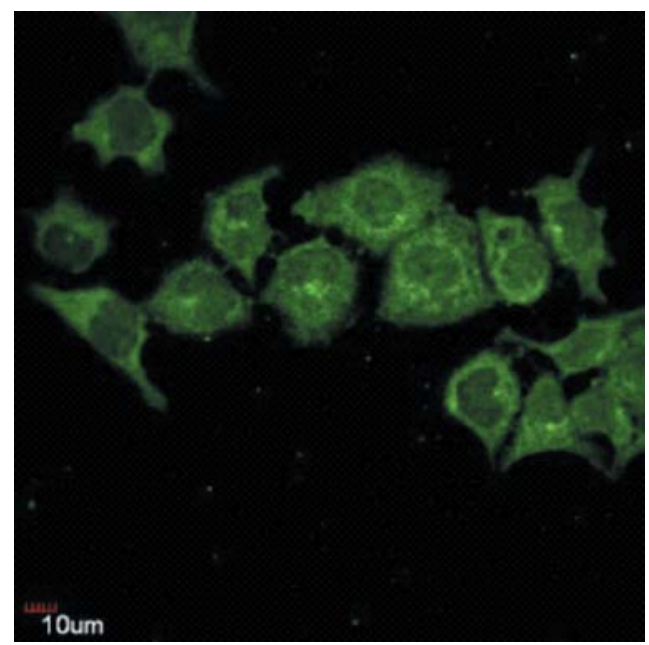

Ab

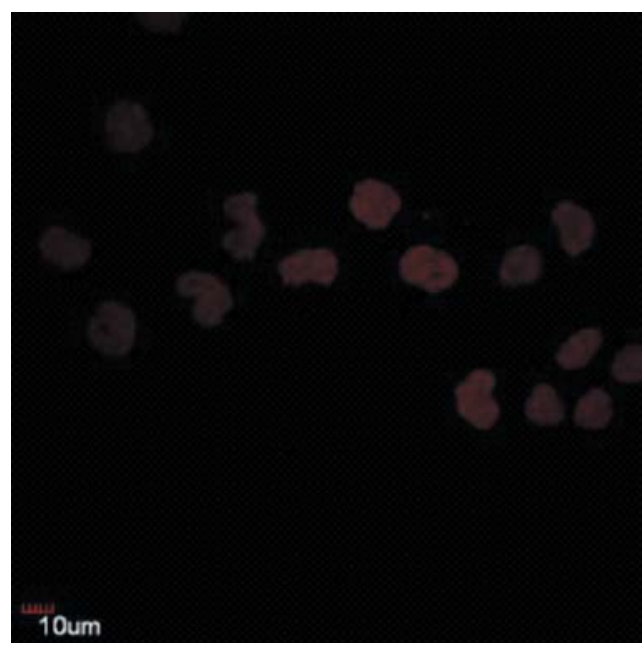

Ac

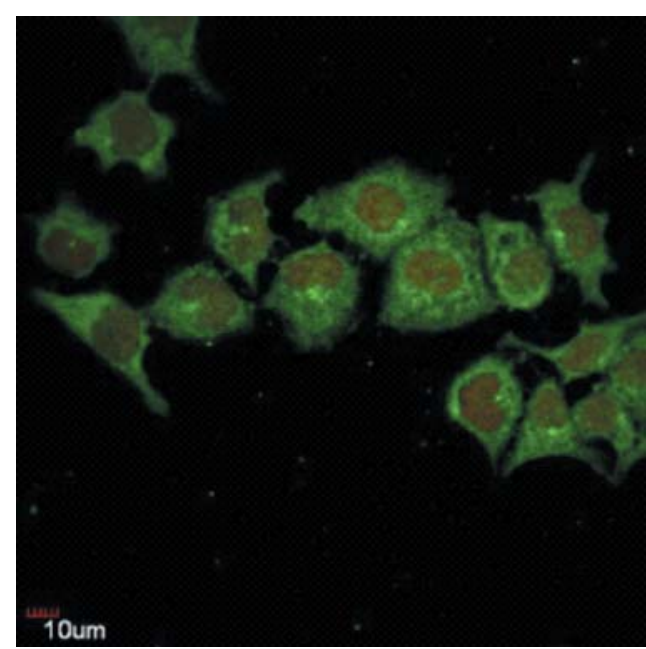

Ba

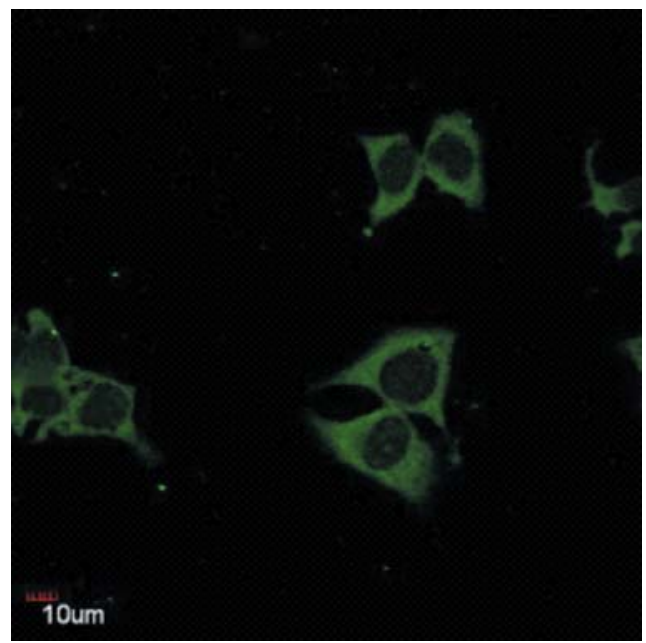

Bb

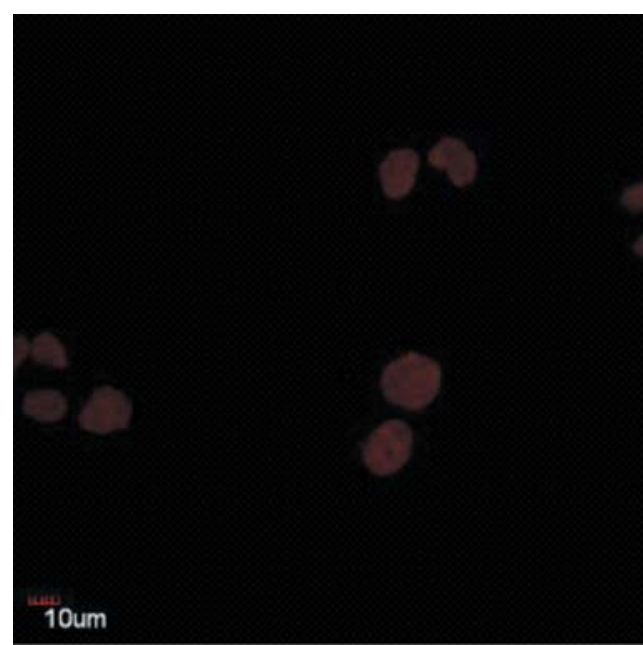

Bc

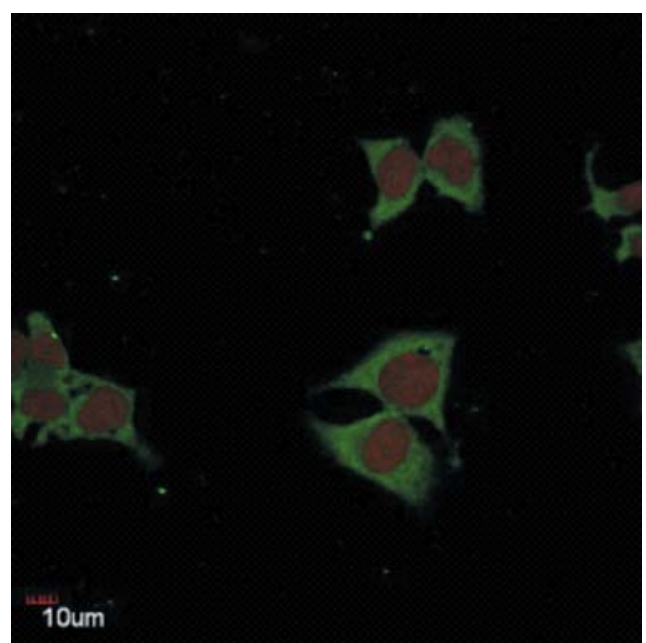

Figure 4. (A) Active- $\beta$-catenin intracellular position expression in EC Ishikawa cells. Active- $\beta$-catenin (green fluorescence) was intensely stained in cytoplasm and nucleus. Cell nucleus appeared as red fluorescence. Immunofluorescence x600 Bar $=10 \mu \mathrm{m}$. (B) Alteration of active- $\beta$-catenin expression intracellular position by DKK1 in EC Ishikawa cells. Treatment with DKK1 for $24 \mathrm{~h}$, active- $\beta$-catenin staining in nucleus was diffused and only weak staining was localized to the cytoplasm. Intracellular position pattern of active-ß-catenin was altered by DKK1. Immunofluorescence x600 Bar $=10 \mu \mathrm{m}$.

We further investigated the correlation of DKK1 and active- $\beta$-catenin expression level to confirm the exact DKK1 regulation mechanism in Wnt signaling pathway of EC. It was shown that treatment with DKK1 for $72 \mathrm{~h}$ gradually decreased the protein expression level of active- $\beta$-catenin (Fig. 3). Thus, DKK1 inhibited Wnt signaling pathway by down-regulating active- $\beta$-catenin. Interestingly, we observed that the distribution of active- $\beta$-catenin was changed by 
Table III. Correlation between DKK1 expression level and clinicopathological characteristics in endometrial carcinoma.

Clinicopathological characteristics

Pathological categories

Endometrial adenocarcinoma

Others

Histological differentiation

Well-differentiated

Moderate differentiated, low-differentiated and undifferentiated

Clinical stage (FIGO 2000)

Stage I

Stage II, III and IV

Lymph node metastasis

No

Yes
No. of low expression No. of high expression P-value

$\begin{array}{rrr}13 & 4 & >0.05 \\ 7 & 6 & \\ 7 & 9 & <0.05 \\ 13 & 1 & \\ & & \\ 8 & 9 & <0.01 \\ 12 & 1 & \\ & & \\ 17 & 10 & \\ 3 & 0 & \end{array}$

A

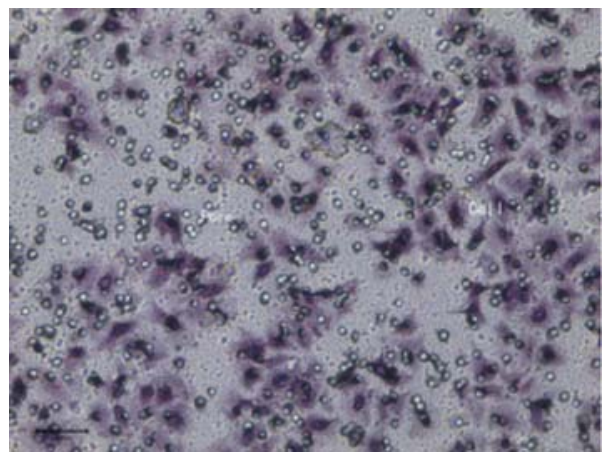

B

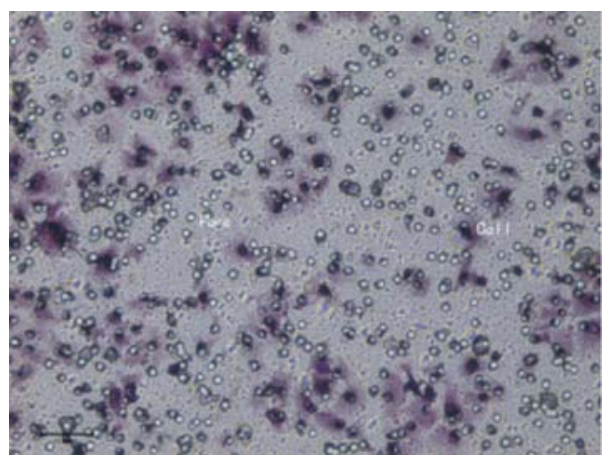

C

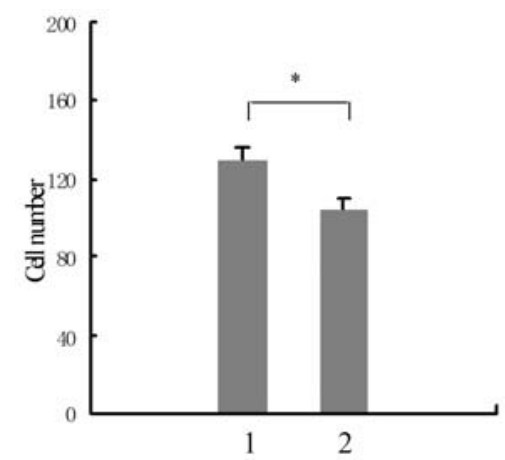

Figure 5. Invasiveness-related biology function of DKK1 in EC Ishikawa cells. (1) Control group; (2) DKK1 group. Treatment with DKK1 for $24 \mathrm{~h}$, average cell number (105.40) penetrating matrigel matrix and pore was decreased significantly as compared to control group (129.70). ${ }^{*} \mathrm{P}<0.01$. Chamber invasiveness assay, HE x200 Bar $=50 \mu \mathrm{m}$.
DKK1 to confocal. Usually, $\beta$-catenin was activated and accumulated in the cytoplasm, and then translocated into the nucleus. Intense staining of active- $\beta$-catenin was seen in cytoplasm and nucleus of Ishikawa cells (Fig. 4A). In treatment with exogenous DKK1, increased DKK1 binding to LRP5/6 inhibited Wnt signaling translocation into cytoplasm, which lead to degradation of $\beta$-catenin. Activeß-catenin was dramatically decreased in the cytoplasm and absent in the nucleus (Fig. 4B). Intracellular position pattern of active- $\beta$-catenin in EC Ishikawa cells was altered by DKK1.

As reported in our study, DKK1 expression level was decreased during the process of benign endometrium transforming to EC. With less DKK1, polymerization of LRP5/6 and DKK1 was reduced, which allowed more free LRP5/6 to interact with frizzled and promoted intracellular Wnt signaling transduction leading to dephosphorylation of $\beta$-catenin. Wnt signaling pathway was activated eventually (28). DKK1 negative regulatory function would be gradually lost with lower and lower DKK1 resulting in exacerbation of endometrial carcinogenesis. These results suggested that, at least in part, DKK1 is involved in genesis and development of EC inducing abnormalities of Wnt signal pathway. Similar expression profiles were also seen in some other tumors. Sato et al (29) demonstrated that DKK genes were frequently silenced in colorectal cancer cells, but not in normal colon mucosa and loss of DKKs facilitated tumorigenesis. In human cytotrophoblast cells, DKK1 was prominently expressed, but absent in human placental choriocarcinoma cell line JAR and JEG3, which implicated some correlations between DKK1 and carcinogenesis of placental choriocarcinoma (30). In majority (69\%) of non-small cell lung cancer cell lines, Wnt signaling pathway remained active and DKK1 was silent (31).

In order to make clear the exact phase of DKK1 acting on the process of benign endometrium transforming to EC, we investigated the potential correlations between DKK1 expression level and certain clinicopathological characteristics (pathology categories, histological differentiation, clinical stages and lymph node metastasis) in EC. We found that well-differentiated EC had the highest expression level. 
Likewise, EC at clinical stage I had higher expression than those at other stages. DKK1 expression correlated well with histological differentiation and clinical stage. However, DKK1 expression level did not show any correlations with pathology categories and lymph nodes metastasis. DKK1 expression exhibited a tendency for decrease during EC progression hinting that DKK1 acted on genesis and early phase of EC. In the late phase (e.g. lymph node metastasis), DKK1 action was absent.

How does DKK1 act on genesis and development of EC? Invasiveness is an important biology behavior of cancer cells and plays a particular role in tumorigenesis and progression. For this reason, we attempted to explore probable relation of DKK1 and invasiveness in EC. We found that treatment with exogenous DKK1 $(0.2 \mathrm{mg} / \mathrm{ml})$ for $24 \mathrm{~h}$, cell invasiveness was decreased by $18.74 \%$ compared to control group. Invasiveness of EC cells in vitro was suppressed by exogenous DKK1. Therefore, DKK1 exhibited a novel invasiveness-related biology function. Nonetheless, the definite mechanism still remains unclear. Currently, little direct evidence of other tumors has been collected in this regard. In addition, it is known that invasion is an early event during genesis and development of malignant tumors. This result also suggested that DKK1 acted on genesis and the early phase of EC. Our studies are underway to clarify the molecular mechanisms by which DKK1 suppresses invasiveness of EC.

In summary, results of our study exhibited DKK1 expression profiles during the process of benign endometrium transforming to EC and suggested that DKK1 is involved in genesis and early phase of EC by suppressing the invasiveness via Wnt signal transduction pathway. DKK1 shows promise as a biomarker for screening the progression of EC, and reactivation of the DKK1 gene could be a valuable strategy for treatment and/or prevention of EC.

\section{References}

1. Terstappen GC, Gaviraghi G and Caricasole A: The WNT signaling pathway as a target for the treatment of neurodegenerative disorders. IDrugs 9: 35-38, 2006.

2. Biena $\mathrm{M}$ and Clevers $\mathrm{H}$ : Linking colorectal cancer to wht signaling. Cell 103: 311-320, 2000.

3. Logan CY and Nusse R: The Wnt signaling pathway in development and disease. Annu Rev Cell Dev Biol 20: 781-810, 2004.

4. Collavin L and Kirschner MW: The secreted Frizzled-related protein Sizzled functions as a negative feedback regulator of extreme ventral mesoderm. Development 130: 805-816, 2003.

5. Mao B, Wu W, Li Y, Hoppe D, Stannek P, Glinka A and Niehrs C: LDL-receptor-related protein 6 is a receptor for Dickkopf proteins. Nature 411: 321-325, 2001.

6. Taniguchi H, Yamamoto H, Akutsu N, Nosho K, Adachi Y, Imai K and Shinomura Y: Transcriptional silencing of hedgehoginteracting protein by $\mathrm{CpG}$ hypermethylation and chromatic structure in human gastrointestinal cancer. J Pathol 213: 131-139, 2007.

7. Miyamoto N, Yamamoto H, Taniguchi H, et al: Differential expression of angiogenesis-related genes in human gastric cancers with and those without high-frequency microsatellite instability. Cancer Lett 254: 42-53, 2007.

8. Zhang H , Xu L, Xiao D, et al: Fascin is a potential biomarker for early-stage oesophageal squamous cell carcinoma. J Clin Pathol 59: 958-964, 2006.
9. Taniguchi H, Yamamoto H, Hirata T, et al: Frequent epigenetic inactivation of Wnt inhibitory factor-1 in human gastrointestinal cancers. Oncogene 24: 7946-7952, 2005.

10. Muller A, Homey B, Soto H, et al: Involvement of chemokine receptors in breast cancer metastasis. Nature 410: 50-56, 2001.

11. Ram ES, Goldman S, Gabarin D and Shalev E: Expression and importance of matrix metalloproteinase 2 and 9 (MMP-2 and -9) in human trophoblast invasion. Reprod Biol Endocrinol 2: 59, 2004.

12. Staff AC, Ranheim T and Henriksen T: 8-Iso-prostaglandin $\mathrm{f}(2 \mathrm{alpha})$ reduces trophoblast invasion and matrix metalloproteinase activity. Hypertension 35: 1307-1313, 2000.

13. Yamamoto H, Vinitketkumnuen A, Adachi Y, et al: Association of matrilysin-2 (MMP-26) expression with tumor progression and activation of MMP-9 in esophageal squamous cell carcinoma. Carcinogenesis 25: 2353-2360, 2004.

14. Akhmedkhanov A, Jacquotte AZ and Toniolo P: Role of exogenous and endogenous hormones in endometrial cancer: review of the evidence and research perspectives. Ann NY Acad Sci 943: 296-315, 2001.

15. Mao J, Wang J, Liu B, et al: Low-density lipoprotein receptorrelated protein-5 binds to Axin and regulates the canonical Wnt signaling pathway. Mol Cell 7: 801-809, 2001.

16. Giles RH, van Es JH and Clevers H: Caught up in a Wnt storm: Wnt signaling in cancer. Biochim Biophys Acta 1653: 1-24, 2003.

17. Maniatis T: A ubiquitin ligase complex essential for the NFkappaB, Wnt/Wingless, and Hedgehog signaling pathways. Genes Dev 13: 505-510, 1999.

18. Crawford HC, Fingleton BM, Rudolph-Owen LA, Goss KJ, Rubinfeld B, Polakis P and Matrisian LM: The metalloproteinase matrilysin is a target of beta-catenin transactivation in intestinal tumors. Oncogene 18: 2883-2891, 1999.

19. Tetsu $\mathrm{O}$ and McCormick F: Beta-catenin regulates expression of cyclin D1 in colon carcinoma cells. Nature 398: 422-426, 1999.

20. Polakis P: Wnt signaling and cancer. Genes Dev 14: 1837-1851, 2000.

21. Weeraratna AT, Jiang Y, Hostetter G, Rosenblatt K, Duray P, Bittner $\mathrm{M}$ and Trent JM: Wnt5a signaling directly affects cell motility and invasion of metastatic melanoma. Cancer Cell 1: 279-288, 2002

22. Qiang YW, Endo Y, Rubin JS and Rudikoff S: Wnt signaling in B-cell neoplasia. Oncogene 22: 1536-1545, 2003.

23. Soon LL, Yie TA, Shvarts A, Levine AJ, Su F and TchouWong KM: Overexpression of WISP-1 down-regulated motility and invasion of lung cancer cells through inhibition of Rac activation. J Biol Chem 278: 11465-11470, 2003.

24. Bafico A, Liu G, Goldin L, Harris V and Aaronson SA: An autocrine mechanism for constitutive Wnt pathway activation in human cancer cells. Cancer Cell 6: 497-506, 2004.

25. Fedi P, Bafico A, Nieto Soria A, et al: Isolation and biochemical characterization of the human Dkk-1 homologue, a novel inhibitor of mammalian Wnt signaling. J Biol Chem 274: 19465-19472, 1999.

26. Mao B and Niehrs C: Kremen2 modulates Dickkopf2 activity during Wnt/LRP6 signaling. Gene 302: 179-183, 2003.

27. Gonzalez-Sancho JM, Aguilera O, Garcia JM, et al: The Wnt antagonist DICKKOPF-1 gene is a downstream target of betacatenin/TCF and is downregulated in human colon cancer. Oncogene 24: 1098-1103, 2005.

28. Bafico A, Liu G, Yaniv A, Gazit A and Aaronson SA: Novel mechanism of Wnt signaling inhibition mediated by DKK1 interaction with LRP6/Arrow. Nat Cell Biol 3: 683-686, 2001.

29. Sato H, Suzuki H, Toyota M, et al: Frequent epigenetic inactivation of DICKKOPF family genes in human gastrointestinal tumors. Carcinogenesis 28: 2459-2466, 2007.

30. Peng S, Miao C, Li J, Fan X, Cao Y and Duan E: Dickkopf-1 induced apoptosis in human placental choriocarcinoma is independent of canonical Wnt signaling. Biochem Biophys Res Commun 350: 641-647, 2006.

31. Licchesi JD, Westra WH, Hooker CM, Machida EO, Baylin SB and Herman JG: Epigenetic alteration of Wnt pathway antagonists in progressive glandular neoplasia of the lung. Carcinogenesis 29: 895-904, 2008. 